\title{
Effect of single bacterial starter culture on odour reduction during controlled fermentation of cassava tubers for foofoo production
}

\author{
Henshaw, E. E.* and Ikpoh, I. S. \\ Department of Microbiology, Faculty of Science, University of Calabar, Calabar, Nigeria. \\ E-mail: henzefilo@yahoo.com \\ Received 16 June 2009; received in revised form 15 September 2009; accepted 14 October 2009
}

\begin{abstract}
Effects of single bacterial starter culture on odour reduction during controlled fermentation of cassava tubers for foofoo production were investigated. Pure cultures were used to ferment cassava tubers in water for $96 \mathrm{~h}$. The cultures used include Bacillus subtilis, Klebsiela sp., Lactobacillus plantarum and Leuconostoc mesenteroides. L. plantarum exhibited the highest acid producing ability, decreasing the $\mathrm{pH}$ of the Cassava tubers from 6.2 to 3.68 with a corresponding increase in total titratable acidity (TTA) from $0.082 \%$ to $0.290 \%$ during the $96 \mathrm{~h}$ fermentation period. The effected changes in $\mathrm{pH}$ and TTA by other organisms ranged respectively from 4.88 and $0.135 \%$ for Klebsiella sp., 4.68 and $0.136 \%$ for L. mesenteroides to 4.90 and $0.139 \%$ for B. subtilis with in the period. All the cultures were found to contribute in varying degree to odour reduction in fermented cassava; B. subtilis effected the highest odour reduction followed by L. plantarum.
\end{abstract}

Keywords: bacterial starter culture, odour reduction, fermented cassava, foofoo

\section{INTRODUCTION}

Cassava (Manihot esculent crantz) is a dicotyledonous plant which originated from Latin America and has been cultivated in other parts of the world. It is an important staple food crop for millions of people in the tropics. Cassava roots are normally processed before consumption. Various fermented cassava products are available, this include garri, foofoo, lafun etc. (Oyewole, 1992).

Fermentation of cassava for 'foofoo' production entails peeling, washing and soaking submerge of cassava tubers in water for 3 - 4 days. During this period, the retted cassava tubers are softened. The softened pulpy mass is then disintegrated in water and passed through a coarse sieve. This separates the fiber from starch which is allowed to sediment then the water is decanted. It is then packed into cloth bags and excess water is squeezed out. The resulted excess meal is white and crumbly which is usually cooked before being eaten (Ihekoronye and Ngoddy, 1985). Foofoo is reconstituted by stirring in boiling water to form a dough and eaten with flavoured sauces (Pelczar et al., 1993). Cassava farming population have empirically developed several processing methods for stabilizing cassava and reducing its toxicity (Coffey et al., 1991). The single problem associated with foofoo consumption is the high offensive odour associated with it. The products of the breakdown of cyanogenic glucoside give-off this offensive odour and at the same time reduced the compound to safe level by traditional method of processing and preparing cassava for consumption by fermentation (Okafor, 1998).
Many studies have been carried out on cassava fermentation for the production of foofoo. Information is not available on the effects of bacterial starter culture on odour reduction during cassava fermentation for foofoo acceptability. Such information is necessary for commercializing traditional food processing method.

\section{MATERIALS AND METHODS}

\section{Media used}

The following media were used for growth studies of pure cultures. Nutrient agar (NA) (Oxoid) (Difco, MI, USA) for $B$. subtilis and Klebsiella sp., Demann Rogosa and sharpe (MRS) agar (Oxoid) (Difco, MI, USA) for L. plantarum and Garvies(1986) medium (Oxoid) (Difco, MI, USA) for $L$. mesenteroides.

\section{Source of cassava}

Cassava tubers of varieties SRP 20424 and SLP 31411 were obtained from University farm of the University of Calabar, Nigeria. The tubers were from $9-11$ months old plants.

\section{Preparation of tuber}

Peeled cassava tubers were cut into uniform sized piece (12 mm diameter x $42 \mathrm{~mm}$ ) with a cork borer. The tuber pieces were sterilized with $0.1 \%$ mercury chloride in $80 \%$ alcohol by the method of Oyewole(1990). One hundred and thirty gram of the sterilized tubers were steeped in 
$150 \mathrm{~mL}$ of sterile distilled water contained in a previously sterilized beaker which was covered with sterilized aluminium foil.

\section{Preparation and inoculation of starter culture}

Pure cultures of bacteria which had earlier been isolated from fermenting cassava and confirmed by molecular technique using $\mathrm{G}+\mathrm{C}$ ratio for identification according to (Coffey et al.,1991,Zhong et al.,1998) were obtained from the Industrial Microbiology Laboratory of the University of Calabar, Calabar. These include $B$. subtilis (RN02), Klebsiella sp. (RN29), L. plantarum (RR 182) and $L$. mensentoroides (Q247). The strains were selected base on an earlier finding as reported by Oyewole (1990; 1992). Pure culture inocula were made from suspension of bacteria cells on NA (Oxoid), Garvies (1956) (Oxoid) medium and de Mann Rogosa and Sharpe (MRS) (Oxoid) agar slants appropriate following the method of Oyewole(1990). Ten $\mathrm{ml}$ of sterile peptone water were added to 18-24 hold cultures on slants and shaken to make a suspension. Dilution of cultures were made so that $1 \mathrm{~mL}$ of inoculums would produce a concentration of approximately $10^{6}-10^{7} \mathrm{cfu} / \mathrm{mL}$ using a pre-fixed absorbance read at $660 \mathrm{~nm}$ against sterile peptone water. Three $\mathrm{ml}$ portions of the respective suspension were used as inocula for $130 \mathrm{~g}$ of sterilized cassava tubers steeped in $150 \mathrm{~mL}$ of sterile distilled water. Uninoculated sterilized, cassava tubers similarly steeped served as control.

\section{Analysis}

The extent of fermentation and the effectiveness of each inoculum on odour reduction were analyzed with the following parameters.

pH

A twelve gram portion of the fermenting tubers was removed aseptically at different times $(0,12,24,36,48$, $60,72,84$ and $96 \mathrm{~h}$ ) and homogenized in $100 \mathrm{~mL}$ of sterile distilled water. The resulting suspension was decanted and its $\mathrm{pH}$ determined by a Kent $\mathrm{pH}$ meter (Kent Industries Measurement Ltd, Surrey, England) model 7020 equipped with a glass electrode.

\section{Total Titratable Acidity (TTA)}

Total titrated acidity expressed as percentage of lactic acid of the fermenting Cassava tubers was determined by titrating $25 \mathrm{~mL}$ of the decanted homogenate samples used for $\mathrm{pH}$ determination against $0.2 \mathrm{~N} \mathrm{NaOH}$ to $\mathrm{pH} 8.42$.

The TTA was calculated with the equation below:

$$
\% \operatorname{acid}(\mathrm{wt} / \mathrm{vol} .)=\frac{\mathrm{N} \times \mathrm{V}_{1} \times \mathrm{E}_{\text {qut }}}{\mathrm{V}_{2} \times 1000} \times 100
$$

Where:

$\mathrm{N}=$ Normality of titrant $(\mathrm{NaOH})$

$\mathrm{V}_{1}=$ Volume of titrant $(\mathrm{NaOH})$
$\mathrm{E}_{\mathrm{qwt}}=$ Equivalent weight of acid $\left(\mathrm{mg} / \mathrm{mE}_{\mathrm{q}}\right)$

$\mathrm{V}_{2}=$ Volume of sample $(\mathrm{mL})$

$1000=$ factor relating $\mathrm{mg}$ to gram $(\mathrm{mg} / \mathrm{g})$

\section{Sensory evaluation}

A 10-man trained panel to determine the acceptability of fermented cassava product 'foofoo' was set up. A 5-point hedonic rating on the degrees of acceptability was conducted with score ' 5 ' having excellent odour reduction and score ' 1 ' for very low odour reduction for the attribute.

Each of the product 'foofoo' was considered against a standard commercial 'foofoo', and was presented to the panelists' one at a time. The final scores represent the means of all panelist impressions.

\section{Growth studies}

Growth of the pure inoculants on cassava tubers was monitored during the $96 \mathrm{~h}$ fermentation period. Eight grams of respectively inoculated tubers were homogenized with $50 \mathrm{~mL}$ of sterile $0.1 \%$ peptone waters to form pulp. The pulp was serially diluted and plated using the spread plate method under aseptic conditions. Total viable counts were made on NA for Klebsiella sp. and $B$. substilis, Garvies (1986) medium for $L$. mesenteroide and MRS agar incubated under anaerobic condition (BBL Gas Pak. $\mathrm{H}_{2}$ and $\mathrm{CO}_{2}$ anaerobic system, Bectone Dickinson) for $L$. plantarum inoculant. Plates were incubated at $30{ }^{\circ} \mathrm{C}$ for $24 \mathrm{~h}$ and $37^{\circ} \mathrm{C}$ for $L$. plantarum plates.

\section{RESULTS}

Changes in the $\mathrm{pH}$ of fermented cassava tubers inoculated with the various pure cultures are presented in Figure 1 and the statistical data is presented on Table $1 . L$. plantarum affected a decrease in the $\mathrm{pH}$ from 6.2 to 3.68 after $96 \mathrm{~h}$ of fermentation $B$. subtilis affect an initial slight increase in $\mathrm{pH}$ which later decreased to 4.90 at the end of the fermentation. Klebsiella sp. and $L$. mesenteroides effected reductions to $\mathrm{pH} 4.88$ and 4.68 respectively.

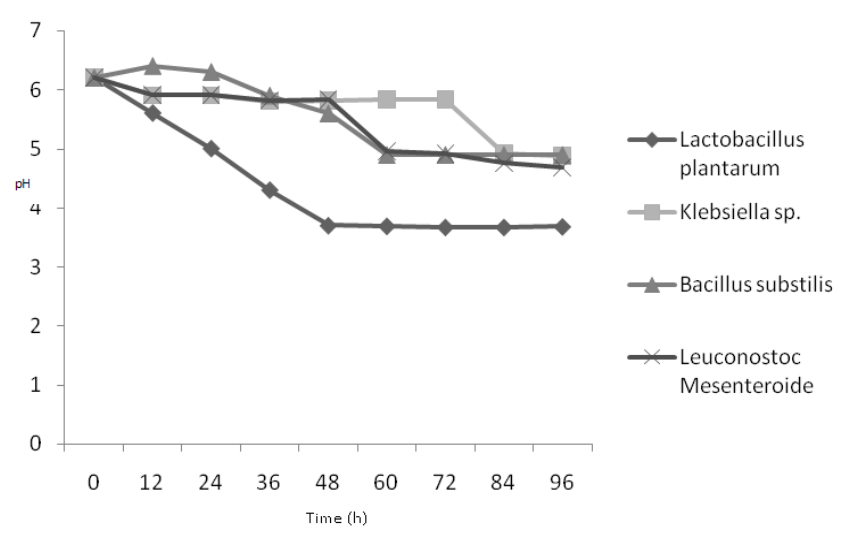

Figure 1: $\mathrm{pH}$ changes during fermentation with single pure cultures 
Table 1: $\mathrm{pH}^{*}$ changes during fermentation with single pure culture for different length of time (\% lactic acid)

\begin{tabular}{|c|c|c|c|c|c|c|c|c|c|}
\hline \multirow{2}{*}{ 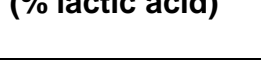 } & & & & & 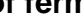 & 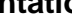 & & & \\
\hline & 0 & 12 & 24 & 36 & 48 & 60 & 72 & 84 & 96 \\
\hline L. plantarum & 6.2 & 5.6 & 5.0 & 4.3 & 3.7 & 3.69 & 3.67 & 3.67 & 3.68 \\
\hline L. mesenteroides & 6.2 & 5.9 & 5.9 & 5.82 & 5.83 & 4.95 & 4.92 & 4.75 & 4.68 \\
\hline Klebsiella sp. & 6.2 & 5.9 & 5.9 & 5.8 & 5.81 & 5.83 & 5.83 & 4.92 & 4.88 \\
\hline B. subtilis & 6.2 & 6.4 & 6.3 & 5.9 & 5.6 & 4.90 & 4.90 & 4.90 & 4.90 \\
\hline
\end{tabular}

${ }^{*}$ Values are means of triplicate determination

Table 2: Total titratable acidity $(\%)^{\star}$ as lactic acid for different length of time

\begin{tabular}{llllllllll}
\hline (\% lactic acid) & \multicolumn{7}{c}{ Period of fermentation (h) } \\
\cline { 2 - 10 } & $\mathbf{0}$ & $\mathbf{1 2}$ & $\mathbf{2 4}$ & $\mathbf{3 6}$ & $\mathbf{4 8}$ & $\mathbf{6 0}$ & $\mathbf{7 2}$ & $\mathbf{8 4}$ & $\mathbf{9 6}$ \\
\hline L. plantarum & 0.082 & 0.12 & 0.15 & 0.17 & 0.20 & 0.23 & 0.25 & 0.27 & 0.29 \\
\hline L. mesenteroides & 0.082 & 0.082 & 0.084 & 0.085 & 0.085 & 0.130 & 0.131 & 0.134 & 0.136 \\
Klebsiella sp. & 0.082 & 0.082 & 0.130 & 0.120 & 0.120 & 0.131 & 0.133 & 0.134 & 0.135 \\
B. subtilis & 0.082 & 0.082 & 0.083 & 0.089 & 0.11 & 0.131 & 0.132 & 0.137 & 0.139 \\
\hline
\end{tabular}

${ }^{*}$ Values are means of triplicate determination

Table 3: Growth of single pure cultures on cassava tubers for different length of time

\begin{tabular}{llllllllll}
\hline $\begin{array}{l}\mathbf{l}_{\mathbf{l o g}} \mathbf{1 0} \times \mathbf{1 0}^{\prime} \\
\text { cfu/g }\end{array}$ & $\mathbf{0}$ & $\mathbf{1 2}$ & $\mathbf{2 4}$ & $\mathbf{3 6}$ & $\mathbf{4 8}$ & $\mathbf{6 0}$ & $\mathbf{7 2}$ & $\mathbf{8 4}$ & $\mathbf{9 6}$ \\
\hline L. plantarum & $8.2 \pm 0.12$ & $9.5 \pm 0.05$ & $10 \pm 0.11$ & $10.9 \pm 0.1$ & $11.1 \pm 0.1$ & $12.2 \pm 0.11$ & $12.9 \pm 0.11$ & $13.1 \pm 0.11$ & $13.3 \pm 0.11$ \\
L. mesenteroides & $7.0 \pm 0.11$ & $7.2 \pm 0.5$ & $7.8 \pm 0.5$ & $7.9 \pm 0.5$ & $8.1 \pm 0.11$ & $8.8 \pm 0.12$ & $9 \pm 0.5$ & $9.3 \pm 0.05$ & $10.0 \pm 0.11$ \\
Klebsiella sp. & $8.2 \pm 0.12$ & $9 \pm 0.11$ & $9.2 \pm 0.11$ & $8.8 \pm 0.5$ & $9 \pm 0.5$ & $9.2 \pm 0.5$ & $9.3 \pm 0.05$ & $9.2 \pm 0.05$ & $9.2 \pm 0.05$ \\
B. subtilis & $8.1 \pm 0.11$ & $8.9 \pm 0.12$ & $9 \pm 0.5$ & $8.8 \pm 0.11$ & $8.9 \pm 0.12$ & $9.1 \pm 0.5$ & $8.1 \pm 0.11$ & $8.2 \pm 0.11$ & $7.9 \pm 0.05$ \\
\hline
\end{tabular}

${ }^{*}$ Values are the mean \pm S.E of three replicate

The TTA changes of the cassava tubers inoculated with the culture are shown in figure 2 and statistical data is presented on table 2. L. plantarum produced the highest increase in TTA content from $0.082 \%$ at $0 \mathrm{~h}$ to $0.290 \%$ after $96 \mathrm{~h}$. The abilities of other inocula to effect acid production are relatively low. $B$. subtilis, Klebsiella sp. and L. mesenteriods increased the TTA from $0.082 \%$ at $0 \mathrm{~h}$ to $0.139 \%, 0.135 \%$ and $0.136 \%$ respectively after $96 \mathrm{~h}$ fermentation period.

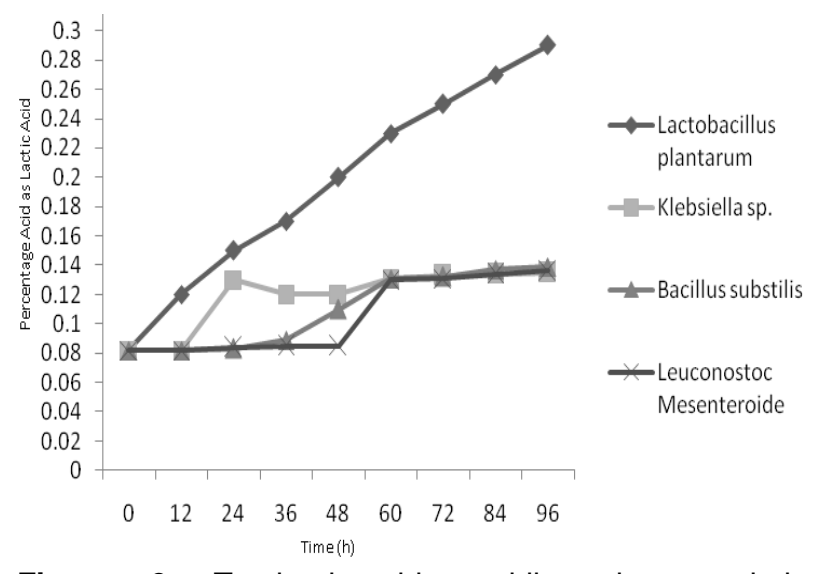

Figure 2: Total titratable acidity change during fermentation using bacterial pure culture
The growth patterns of the pure inocula on the cassava tubers are shown in figure 3 and the statistical data is presented in table 3 . L. plantarum grew relatively better than others. The population of $B$. subtilis remained almost constant for most part, with a slight decreased in population towards the end of the fermentation. Klebsiella $s p$. population increased slightly within the first $24 \mathrm{~h}$, remained constant for the remaining period, while $L$. mesenteroides showed the same pattern as in Klebsiella sp.

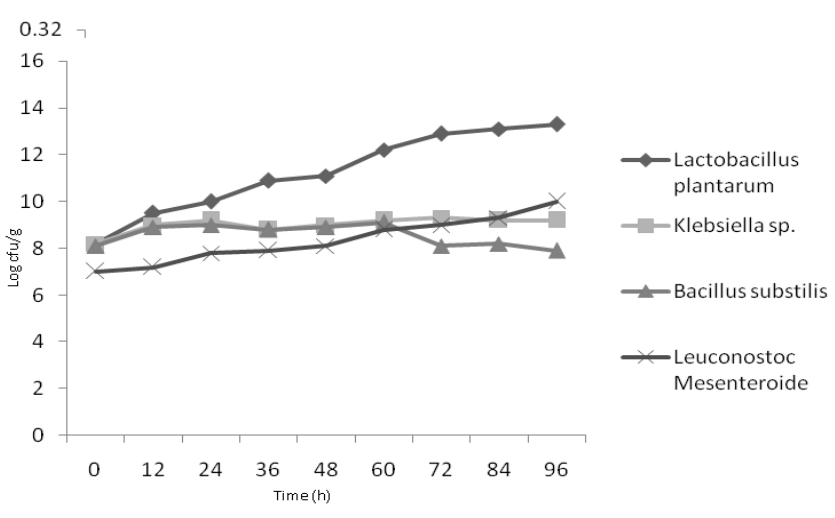

Figure 3: Growth of single bacterial pure culture on fermenting cassava tubers. 
Table 4: Sensory* rating of pure inocula for odour reduction for different length of time

\begin{tabular}{|c|c|c|c|c|c|c|c|c|c|}
\hline \multirow[t]{2}{*}{ (\% lactic acid) } & \multicolumn{9}{|c|}{ Period of fermentation (h) } \\
\hline & 0 & 12 & 24 & 36 & 48 & 60 & 72 & 84 & 96 \\
\hline L. plantarum & 0 & 1.9 & 2.1 & 2.3 & 2.5 & 3.2 & 3.3 & 3.4 & 3.4 \\
\hline L. mesenteroides & 0 & 1.7 & 1.8 & 1.9 & 2.1 & 2.3 & 2.5 & 2.5 & 2.6 \\
\hline Klebsiella sp. & 0 & 1.5 & 1.6 & 1.6 & 1.8 & 1.9 & 2.0 & 2.2 & 2.5 \\
\hline B. subtilis & 0 & 3.5 & 5.0 & 5.0 & 5.0 & 5.0 & 5.0 & 5.0 & 5.0 \\
\hline
\end{tabular}

Table 5: Sensory ${ }^{\star}$ rating of pure inocula for texture for different length of time

\begin{tabular}{llllllllll}
\hline (\% lactic acid) & \multicolumn{8}{c}{ Period of fermentation (h) } \\
\cline { 2 - 11 } & $\mathbf{0}$ & $\mathbf{1 2}$ & $\mathbf{2 4}$ & $\mathbf{3 6}$ & $\mathbf{4 8}$ & $\mathbf{6 0}$ & $\mathbf{7 2}$ & $\mathbf{8 4}$ & $\mathbf{9 6}$ \\
\hline L. plantarum & 0 & 1.2 & 2.4 & 2.5 & 3.0 & 3.1 & 3.4 & 3.4 & 3.4 \\
L. mesenteroides & 0 & 1.0 & 1.3 & 1.5 & 1.6 & 1.8 & 2.5 & 2.6 & 3.0 \\
Klebsiella sp. & 0 & 3.2 & 4.0 & 4.3 & 4.5 & 4.5 & 4.6 & 4.6 & 4.6 \\
B. subtilis & 0 & 1.2 & 1.5 & 1.9 & 2.4 & 3.5 & 3.6 & 3.6 & 4.3 \\
\hline
\end{tabular}

* Values are means of triplicate determination

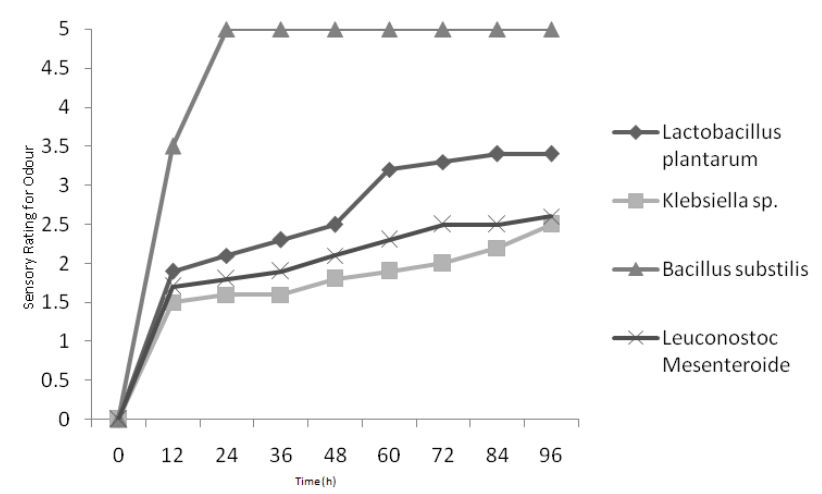

Figure 4: Characteristic foofoo odour reduction by single bacterial pure cultures during cassava fermentation.

The sensory panel rating for odour reduction and texture in fermenting cassava by the single culture inoculants is shown in figure 4 and 5 and the statistica data are presented in table 4 and 5 respectively. $B$. subtilis scored the highest rating for odour reduction ability followed by L. plantarum. None often pure cultures could singly cause satisfactory retting of the tubers (scale $=5.0$ ), but $B$. subtilis showed great odour reduction to an acceptable level.

\section{DISCUSSIONS}

Four pure culture inocula were investigated. L. plantarum was found to give the highest acid producing ability on the fermenting cassava tubers. Oyewole (1990) had earlier reported that $L$. plantarum strain is associated with high acid production during cassava fermentation for the production of foofoo. It appears that L. plantarum and possibly other strains of lactic acid bacteria are responsible for acid production during cassava fermentation process. This view is supported by the

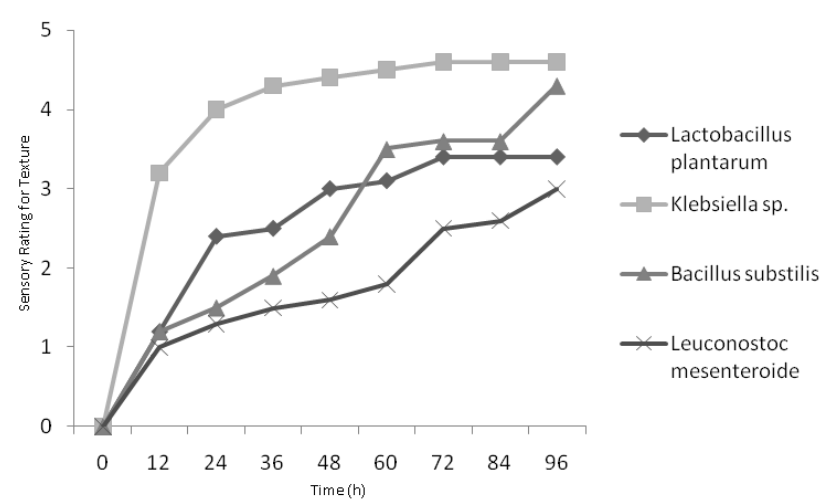

Figure 5: Effect of single bacterial pure culture on the retting juice of fermented cassava

The sensory ratings showed that all the pure culture inocula investigated had varying contributions to odour reduction with $B$. subtilis playing a major role in odour reduction followed by $L$. plantarum. This may be due in part to the fact that $B$. subtilis and $L$. plantarum occur naturally and produces ethanol and high concentration of lactate which strongly acidify the retting juice (Asiedu, 1992). The volatile fatty acid along with lactate produced is responsible for the typical odour in fermented cassava tubers (Brauman et al., 1996). Also the cyanogenic glucoside are been reduced to hydrocyanogenic acid thereby giving off a characteristics odour (Odunfa, 1985) relatively low acid producing abilities of other major strains implicated in the fermentation.

\section{REFERENCES}

Asiedu, J. J. (1992). Processing Tropical Crop In: A Technological Approach. The Macmillan Press Ltd. London and Bassingstoke. pp. 158-162. 
Austin, B. and Fergus, P. (1986). Modern Bacterial Taxonomy Van Nostr and Beinhold, UK. pp. 69-82.

Brauman, A., Keleke, S., Malonya, M., Miambi, E. and Ampe, F. (1996). Microbiological and Biochemical characterization of cassava retting a tradition lactic acid fermentation for foofoo (Cassava Flour) Production. Applied and Environmental Microbiology 62, 28-54.

Coffey, A. G., Costello, V. M., Fitzgerald, G. F. and Daly, C. (1991). Bacteriophage insensitivity in Lactococci with special reference to Pc $18-29$. Dummy, G. (ed.). In: Genetics and Molecular Biology of Streptococci and Lactococci. American Society of Microbiology, Washington, D. C. pp. 131-135

Garvies,E.I.(1986).Genus Leuconostoc In:Bergeys manual of systemic bacteriology Vol.2. Ed. Holt J.G. Pp.1071-1075. Baltimore: William and Wilkins.

Ihekoronye, A. I. and Ngoddy, P. O. (1985). Cassava In: Integrated Food Science and Technology for the Tropics. McGraw Hill Inc. pp. 270-275.

Odunfa, S. A. (1985). African fermentation food. In: Microbiology of fermented food. Wood, B. J. (ed.). Elsevier Applied Science Publishers, London and New York.

Okafor, N. (1998). Indigenous fermentation foods. Nigerian Institute of Food Journal 1(1), 33-37.

Oyewole, O. B. (1990). Optimization of Cassava fermentation for fufu production: Effects of single starter cultures. Journal of Applied Bacteriology 68, 49-54.

Oyewole, O. B. (1992). Cassava processing in Africa. In: Application of Biotechnology to Traditionally Fermented Foods. National Academic Press, Washington DC. pp. 90.

Pelczar, M. J. E. and Noel, R. K. (1993). Industrial Application of Microbiology. In: Microbiology Concepts and Applications. McGraw Hill Inc. pp. 644 -669 .

Zhong, W., Millsap, K., Bialkowska, H. H. and Reid, G. (1998). Differentiation of Lactobacillus species by molecular typing. Applied Environmental Microbiology $68,2418-2423$. 